Egyptian Journal of Aquatic Biology \& Fisheries

Zoology Department, Faculty of Science,

Ain Shams University, Cairo, Egypt.

ISSN $1110-6131$

Vol. 24(1): 173 - 187 (2020)

www.ejabf.journals.ekb.eg

\title{
Optimization of anolyte solution in Microbial Fuel Cell using statistical experimental design
}

\author{
Dalia El S. El-Badan*, Marium A. Khaled and Khaled M. Ghanem \\ Botany and Microbiology Department, Faculty of Science, Alexandria University, Egypt \\ *Corresponding Author: dalia.elbadan@alexu.edu.eg
}

\section{ARTICLE INFO \\ Article History: \\ Received: Jan. 14, 2020 \\ Accepted: Jan. 29, 2020 \\ Online: Jan. 31, 2020}

Keywords:

Microbial fuel cell

MFC

Wastewater

Electricity generation

Experimental design

\begin{abstract}
This study aims to optimize factors that affect power generation in microbial fuel cell (MFC) using a statistical experimental design. A MFC reactor with two compartments has been constructed from cheap materials and used for electricity generation. The performance of MFCs can be influenced by several factors, hence; the Plackett-Burman design was employed to determine the most significant factors that affect power generation. The factors that affected the electricity generation significantly were magnesium sulfate, yeast extract, and sodium acetate. A near optimum medium formulation was obtained using this method with increased power density by $71.57 \%$. In this respect, the three levels Box-Behnken design was applied. A polynomial model was created to correlate the relationship between the three significant variables and power density. Under the optimized condition, the power density was $390 \mathrm{~mW} / \mathrm{m}^{2}$. These results indicate that the optimized conditions accelerated the power generation and the maximum power point (MPP) was about $91.2 \%$ higher than that recorded with the basal condition. Microbial fuel cells (MFCs) are new types of bioreactors that use bacteria to generate electricity from organic and nonorganic compounds and are considered one of the prospective alternative technologies.
\end{abstract}

\section{INTRODUCTION}

Microbial fuel cells (MFCs) are new types of bioreactors, which use exoelectrogenic biofilms for electrochemical energy production (Ulusoy and Dimoglo, 2018; Xu et al., 2019). In recent years, a large number of studies have been conducted to explore microbial fuel cells in many aspects, such as electron transfer mechanisms, enhancing power outputs, reactor developments and applications (Parkash, 2016; Cao et al., 2019).

Many studies practiced the classical optimization methods for bioelectricity generation, which involve the alteration of one factor at a time, while keeping all other factors at a predetermined level (Flimban et al., 2018). In this approach, a series of experiments are carried out using a large number of variables which need to be tested to determine the optimum level. 
This process is very time-consuming, labour-intensive, expensive and the interaction between the variables is ignored (Haaland, 1989; Deng and Tang, 1999; Montgomery, 2012; Scibilia, 2014). On the other hand, for improving the power generation, statistical experimental design approaches were employed. Statistical experimental designs are powerful tools for searching the key factors rapidly from a multivariable system and minimizing the error in determining the effect of parameters. Therefore, results are achieved in an economical manner (Anderson and McLean, 2018).

Optimization of bioelectricity generation using a statistically planned experiment is a sequential process. First, a large number of continuous factors are screened to find the most affecting factors in bioelectricity generation that could be optimized by a response surface modeling (Mabrouk et al., 2013, 2014; Ghanem et al., 2015, 2016; Vilas Boas et al., 2019). Response surface methodology, which is supported by software, is an empirical modelization technique derived to evaluate the relationship between a set of controlled experimental factors and observed results. This optimization process involves three major steps: estimating the coefficients in a mathematical model, predicting the response and checking the adequacy of the model (Ferreira et al., 2007; Annadurai et al., 2008; Mahmoodi-Babolan et al., 2019).

The present work aims to investigate the parameters affecting the performance of dual chamber MFC through statistically designed experiments. First, Plackett-Burman design was applied to screen fot the most significant medium components affecting voltage yield. Second, Box-Behnken design was applied to determine the optimum level of each of the significant parameters.

\section{MATERIALS AND METHODS}

\section{MFC setup}

Double chamber MFC, medium composition, inoculum, and operation conditions were constructed as previously described by El-Badan et al. (2019).

\section{Measurement of Output:}

The output of the MFC was expressed by means of voltages (E) after the MFC had reached steady state. For this purpose, multimeter (SanwaCD800a - Japan) was used and calibrated each time before use. The voltage and current generated were converted to power according to Ohm's law, $\mathrm{P}=\mathrm{IV}$, where, $\mathrm{P}=$ power $(\mathrm{mW}), \mathrm{I}=$ current $(\mathrm{mA})$, and $\mathrm{V}=$ voltage $(\mathrm{mV})$. Power density $\left(\mathrm{mW} / \mathrm{m}^{3}\right)$ and current density $\left(\mathrm{mA} / \mathrm{m}^{3}\right)$ were calculated by dividing power and current by the treated wastewater volume $\left(\mathrm{m}^{3}\right)$. The polarization curve was obtained at different external resistances (100-740 $\Omega$ ). The internal resistance was derived from the polarization curve as the slope (Alshehri et al., 2016). Triplicate of all experiments was done and the average was taken. The standard deviation of the studied parameters ranged between 0.4 and $3.8 \%$.

\section{Plackett-Burman experimental design}

Application of the statistical design was carried out in a "two-phase" optimization approach. The first step was to evaluate relative importance of the various constituents in the culture media 
and selecting levels of variables that have the significant influence on power generation, the second was verification of the experiments to validate results under specific optimized experimental conditions (Huang et al., 2019). The Plackett-Burman experimental design can provide indication and tendency regarding necessity of each factor in relatively few experiments. Seven independent variables were screened in eight combinations organized according to the Plackett-Burman design matrix (Table 1). Each variable was examined at two levels, low (-) and high (+). Main effect of each variable can be calculated using the following standard equation:

$$
\text { Main effect }=\left[\sum \mathrm{R}(\mathrm{H})-\sum \mathrm{R}(\mathrm{L})\right] / \mathrm{N}
$$

Where $\mathrm{R}(\mathrm{H})$ and $\mathrm{R}(\mathrm{L})$ are observations of trials where independent variables were present in high and low concentrations, respectively, and $\mathrm{N}$ is the number of trials divided by 2 .

Another important part of the Plackett-Burman screening design was the choice of dummies (Mohajeri Amiria et al., 2019). A dummy is a component whose level does not change in the design. Factors known to have no effect can be chosen as dummies, or any factor not chosen as a variable can be included as a dummy. In the experiments performed, temperature served as a dummy variable. Excel (Microsoft office, 2010) was used for the experimental design and all statistical analysis. The variables with confidence levels more than $95 \%$ were considered to influence power generation.

\section{Box-Behnken design}

In the second phase of medium formulation for optimum power generation, the Box-Behnken experimental design (Selamat et al., 2018; Mohajeri Amiria et al., 2019), which is a central composite design (Box and Behnken, 1960), was applied. In this model, the most significant independent variables, namely; yeast extract $\left(\mathrm{X}_{1}\right)$, sodium acetate $\left(\mathrm{X}_{2}\right)$, and $\mathrm{MgSO}_{4} \cdot 7 \mathrm{H}_{2} \mathrm{O}\left(\mathrm{X}_{3}\right)$ are included and each factor can be examined at three different levels, low (-), high (+) and central or basal (0). Fifteen combinations were fitted to the following second order polynomial model:

$$
Y=b_{0}+b_{1} X_{1}+b_{2} X_{2}+b_{3} X_{3}+b_{12} X_{1} X_{2}+b_{13} X_{1} X_{3}+b_{23} X_{2} X_{3}+b_{11} X_{1}^{2}+b_{22} X_{2}^{2}+b_{33} X_{3}^{2}
$$

Where, $\mathrm{Y}$ is the dependent variable (MPP); $\mathrm{X}_{1}, \mathrm{X}_{2}$ and $\mathrm{X}_{3}$ are the independent variables; $\mathrm{b}_{0}$ is the regression coefficient at centre point; $b_{1}, b_{2}$ and $b_{3}$ are linear coefficients; $b_{12}, b_{13}$ and $b_{23}$ are second-order interaction coefficients; and $b_{11}, b_{22}$, and $b_{33}$ are quadratic coefficients. The values of the coefficients were calculated using STATISTICA (data analysis software system), version 7, and the optimum concentrations were predicted using Microsoft Excel 2010. The quality of the fit of the polynomial model equation was expressed by the coefficient of determination, $\mathrm{R}^{2}$ (Uwadiae and Ihaza, 2018). Three-dimensional graphical representations were also constructed using STATISTICA software to reflect the effects as well as the interactions of independent variables on the power generation.

\section{RESULTS}

\section{Optimization of medium composition}

The anolyte composition has a great effect on the performance of the microbial fuel cell; it is where bio-electrochemical reactions take place. The composition of the anolyte not only affect 
the type of microorganisms available for electricity generation, but also their electrogenic activity and interactions with each other as well as with the electrode. The performance of the cell is also greatly affected by the ionic strength of the anolyte solution (Logan, 2008; Thygesen et al., 2009; Slate et al., 2019). Therefore, the aim of this experiment was to optimize medium composition for maximum electricity production and to evaluate the factors significantly affecting power generation, using Plackett-Burman experimental design. The Plackett-Burman design for 8 trials with two levels of concentrations for seven different variables was carried out according to the experimental matrix as shown in Table 1. The corresponding results for the seven examined variables were summarized in Table 2.

A large variation in the results of the Plackett-Burman design experiments was observed, the maximum values of voltage, $24.27 \mathrm{mV}$, electric current, $0.728 \mathrm{~mA}$, current density, $0.124 \mathrm{~mA} / \mathrm{cm}^{2}$, electric power, $17.67 \mathrm{~mW}$, power density, $300 \mathrm{~mW} / \mathrm{m}^{2}$, and volumetric power density, $9.5 \mathrm{~mW} / \mathrm{m}^{3}$ was achieved in trial number 1 , while the minimum values of voltage, $14.01 \mathrm{mV}$, electric current, $0.42 \mathrm{~mA}$, current density, $0.071 \mathrm{~mA} / \mathrm{cm}^{2}$, electric power, $5.89 \mathrm{~mW}$, power density, $100 \mathrm{~mW} / \mathrm{m}^{2}$, and volumetric power density, $3.167 \mathrm{~mW} / \mathrm{m}^{3}$ was achieved in trial number 4 (Table 2).

The main effects of the examined variables on the MPP generation were calculated and presented in Table 1. A main effect value with a positive sign indicates that high concentration of this variable is near to optimum and the negative sign indicates that the low concentration of this variable is near to optimum, while a mean close to zero means that a factor has little or no effect. As shown in Table 1, it was found that all of the tested variables, except phosphate buffer solution (PB), had a positive effect on power generation within the test ranges. The highest improvement percentages of 47.1, 31.4, and 17.6\% were observed in trials numbers 1, 2, and 8; respectively (Table 2). Fig. 1 shows the ranking of factor estimates in a Pareto chart.

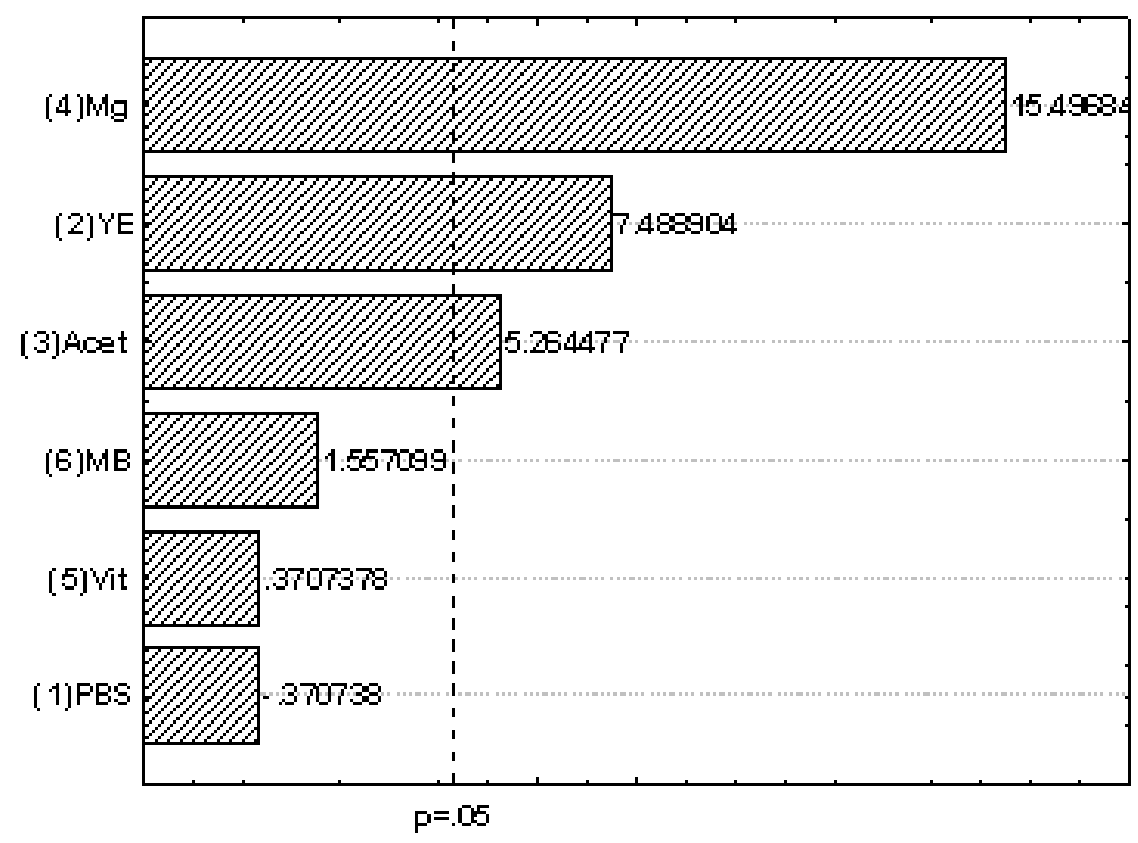

Fig. 1: Pareto chart for Packett-Burman analysis, rationalizing the effect of each variable on power generation. The vertical line indicates confidence level of $95 \%$ for the effects. 
Optimization of anolyte solution in Microbial Fuel Cell

Table 1: Plackett-Burman design matrix and Statistical analysis of results showing estimated effect, corresponding, $p$-value, regression coefficient, and confidence level for each variable on power generation

\begin{tabular}{|c|c|c|c|c|c|c|c|}
\hline \multirow{3}{*}{$\begin{array}{c}\text { Run order/ } \\
\text { Measuring unit }\end{array}$} & \multicolumn{7}{|c|}{ Experimental values } \\
\hline & PB & YE & $\mathbf{S A}$ & Mg & VI & MB & TP* \\
\hline & $\mathbf{m M}$ & $\mathrm{g} / \mathrm{l}$ & $\mathrm{g} / \mathrm{l}$ & $\mathrm{g} / \mathrm{l}$ & Ml & $\mu \mathbf{M}$ & ${ }^{\circ} \mathbf{C}$ \\
\hline 1 & $25(-)$ & $5(+)$ & $8(+)$ & $0.61(+)$ & $0.5(-)$ & $60(-)$ & $30(+)$ \\
\hline 2 & $25(-)$ & $5(+)$ & $2(-)$ & $0.61(+)$ & $1(+)$ & $240(+)$ & $30(+)$ \\
\hline 3 & $100(+)$ & $1(-)$ & $2(-)$ & $0.61(+)$ & $0.5(-)$ & $240(+)$ & $30(-)$ \\
\hline 4 & $25(-)$ & $1(-)$ & $2(-)$ & $0.21(-)$ & $0.5(-)$ & $60(-)$ & $30(+)$ \\
\hline 5 & $25(-)$ & $1(-)$ & $8(+)$ & $0.21(-)$ & $1(+)$ & $240(+)$ & $30(+)$ \\
\hline 6 & $100(+)$ & $5(+)$ & $8(+)$ & $0.21(-)$ & $0.5(-)$ & $240(+)$ & $30(-)$ \\
\hline 7 & $100(+)$ & $5(+)$ & $2(-)$ & $0.21(-)$ & $1(+)$ & $60(-)$ & $30(-)$ \\
\hline 8 & $100(+)$ & $1(-)$ & $8(+)$ & $0.61(+)$ & $1(+)$ & $60(-)$ & $30(-)$ \\
\hline 9 & $50(0)$ & $3(0)$ & $5(0)$ & $0.41(0)$ & $0.75(0)$ & $150(0)$ & $30(0)$ \\
\hline Main Effect & -2.5 & 50.5 & 35.5 & 104.5 & 2.5 & 10.5 & - \\
\hline$p$-value & 0.75 & 0.02 & 0.03 & 0 & 0.75 & 0.26 & - \\
\hline Coefficient regression & -1.2 & 25.3 & 17.8 & 52.3 & 1.3 & 5.3 & - \\
\hline Confidence \% & 25.36 & 98.26 & 96.58 & 99.59 & 25.36 & 74.03 & - \\
\hline
\end{tabular}

* Dummy variable, Phosphate-Buffered Saline solution (PB), Yeast extract (YE), Sodium acetate $(\mathrm{SA}), \mathrm{MgSO}_{4} .7 \mathrm{H}_{2} \mathrm{O}(\mathrm{Mg}), \mathrm{Vitamin}$ solution (VI), Methylene blue (MB), Temperature (TP)

Table 2. Results of Plackett-Burman design

\begin{tabular}{|c|c|c|c|c|c|c|c|}
\hline Trials & $\begin{array}{c}\text { Electric } \\
\text { current } \\
\mathbf{I}_{(33 \Omega)} \\
(\mathbf{m A})\end{array}$ & $\begin{array}{c}\text { Voltage } \\
\mathbf{E}_{(33 \Omega)} \\
(\mathbf{m V})\end{array}$ & $\begin{array}{c}\text { Current } \\
\text { density } \\
\mathbf{I}_{\mathbf{d}} \\
\left(\mathbf{m A} / \mathbf{c m}^{2}\right)\end{array}$ & $\begin{array}{c}\text { Electric } \\
\text { power } \\
\text { P } \\
(\mathrm{mW})\end{array}$ & $\begin{array}{c}\text { Power density } \\
\text { MPP } \\
\left(\mathrm{mW} / \mathrm{m}^{2}\right)\end{array}$ & $\begin{array}{c}\text { Volumetric Power } \\
\text { density } \\
\mathbf{P}_{\mathbf{v}(\mathrm{An})} \\
\left(\mathbf{m W} / \mathbf{m}^{3}\right)\end{array}$ & $\begin{array}{c}\text { Percentage of improvement in } \\
\text { power density }\end{array}$ \\
\hline 1 & 0.728 & 24.27 & 0.124 & 17.67 & 300 & 9.500 & 47.06 \\
\hline 2 & 0.688 & 22.94 & 0.117 & 15.79 & 268 & 8.487 & 31.37 \\
\hline 3 & 0.626 & 20.88 & 0.106 & 13.08 & 222 & 7.030 & 8.82 \\
\hline 4 & 0.420 & 14.01 & 0.071 & 5.89 & 100 & 3.167 & -50.98 \\
\hline 5 & 0.528 & 17.61 & 0.090 & 9.31 & 158 & 5.003 & -22.55 \\
\hline 6 & 0.586 & 19.52 & 0.099 & 11.43 & 194 & 6.143 & -4.90 \\
\hline 7 & 0.532 & 17.72 & 0.090 & 9.42 & 160 & 5.067 & -21.57 \\
\hline 8 & 0.651 & 21.71 & 0.111 & 14.14 & 240 & 7.600 & 17.65 \\
\hline 9 & 0.600 & 20.01 & 0.102 & 12.02 & 204 & 6.460 & 0.00 \\
\hline
\end{tabular}


The Pareto chart has been described as a useful tool for identifying the most important effects. It displays the magnitude of each variable and is a convenient way to view the results of a Plackett- Burman design (Haaland, 1989; Strobel and Sullivan, 1999). In this chart, the length of each bar on a standardized Pareto chart is proportional to the absolute value of its associated regression coefficient or estimated effect.

The $t$ - test for any individual effect allows an evaluation of the probability of finding the observed effect purely by chance. The statistical confidence shown in Table 1, which shows the analysis done for the Plackett-Burman design, was calculated as:

Statistical confidence $=(1-p) * 100$

So, a value of $P=0.05$ corresponded to a statistical confidence of $95 \%$. Hence, any component showing a statistical confidence higher than $95 \%$ was considered significant. Based on the statistical analysis of confidence level of 7 variables (Table 1), yeast extract, sodium acetate, and $\mathrm{MgSO}_{4}$ had confidence levels above $95 \%$ and hence were considered the significant parameters influence power generation. None of these components had a negative effect on power generation.

The goodness of fit of the model was checked by determination coefficient $\left(R^{2}\right)$. In this case, the $\mathrm{R}^{2}$ value was calculated to be 0.9939 , indicated that $99.39 \%$ of the total variability in the response could be explained by this model and only $0.61 \%$ of the total variation were not explained. A regression model with $\mathrm{R}^{2}$ close to 1.0 is considered as having a very high correlation (Yong et al., 2011). Therefore, the present $\mathrm{R}^{2}$ value reflected a very good fit between the observed and predicted responses and implied that the model is reliable for predicting power generation.

After applying the ANOVA statistical test, it was found that the first order models for power generation was satisfactory, the polynomial model equation was proposed to calculate the optimum levels of these variables for power generation can be written as:

$$
\mathrm{Y}=205.1-1.2 * \mathrm{~PB}+25.3 * \mathrm{YE}+17.8 * \mathrm{SA}+52.3 * \mathrm{Mg}+1.3 * \mathrm{VI}+5.3 * \mathrm{MB}
$$

Where Y represents power generation in $\mathrm{mW} / \mathrm{m}^{2}$

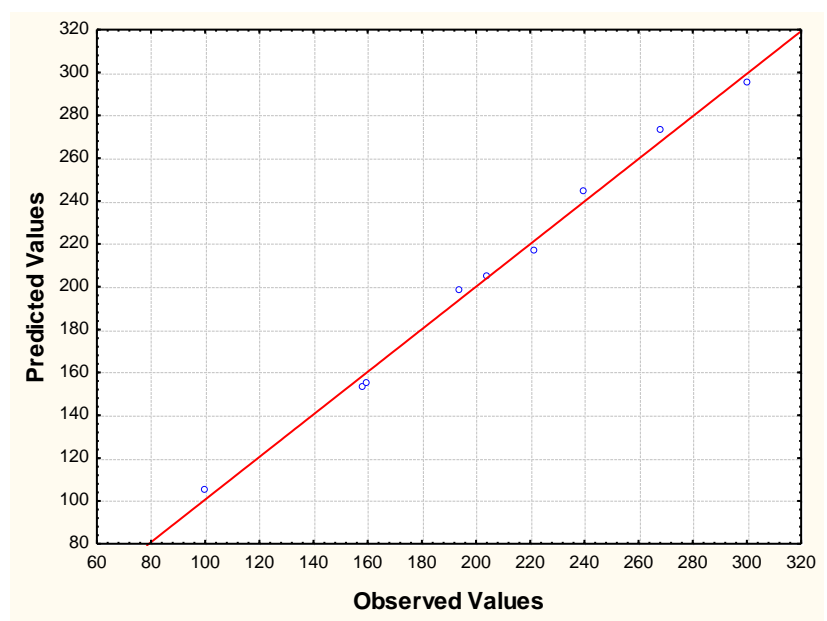

Fig.2: Correlation between predicted and observed values in Plackett-Burman experiment. 


\section{Desirability and prediction profile for power generation}

The maximum experimental value for power generation was $300 \mathrm{~mW} / \mathrm{m}^{2}$, while the predicted response, based on RSM, was estimated to be $295.1 \mathrm{~mW} / \mathrm{m}^{2}$ (Fig. 2). The close correlation between the experimental and predicted data indicates the appropriateness of the model.

\section{Validation of the model}

Based on the data obtained from Plackett-Burman experimental results, the following composition is predicted to be near optimum: $\mathrm{PB}, 25 \mathrm{mM}$; YE, $5 \mathrm{~g} / \mathrm{l} ; \mathrm{SA}, 8 \mathrm{~g} / \mathrm{l} ; \mathrm{Mg}, 0.6$ $\mathrm{g} / \mathrm{l} ; \mathrm{VI}, 1 \mathrm{ml}$; and $\mathrm{MB}, 240 \mu \mathrm{M}$. In order to determine the accuracy of the applied Plackett-Burman screening test, a verification experiment was carried out. The applied near optimum condition resulted in power generation of approximately $350 \mathrm{~mW} / \mathrm{m}^{2}$. This result represented a $71.57 \%$ folds increase in power generation when compared with the average of the results obtained under the basal condition.

\section{Optimization of medium composition by Box-Behnken design}

The variables so identified by Plackett-Burman design were further optimized by RSM using Box-Behnken design experimental plan (Bin Halmi et al., 2016). The three key variables were examined at three different levels $(-, 0,+)$ (Table 3). Table 3 shows various combinations of the three selected variables according to Box-Behnken design. The concentrations of the remaining components in all assemblies were the same as those in the pre-optimized medium of Plackett-Burman design. The polarization data obtained from Box-Behnken experimental design were summarized in Table 4.

The maximal power generated of $380 \mathrm{~mW} / \mathrm{m}^{2}$ was in trial number 5 , with an improvement percentage of 8.6 (Fig. 4) compared with the control (obtained from preoptimized Plackett-Burman design), followed by the trials number 14, and 15; which gave an improvement percentage of 3.4 , and 0.8 , respectively. The maximum experimental value for power generation was $380 \mathrm{~mW} / \mathrm{m}^{2}$, while the predicted response based on the RSM was estimated to be $382.13 \mathrm{~mW} / \mathrm{m}^{2}$ (Table 4). The close correlation between experimental and predicted data indicates the appropriateness of the model.

The analysis of variance (ANOVA) for the response quadratic model is presented in (Table 5). The model was significant at the $99.94 \%$ confidence level and the quality of the model can also be checked using various criteria. Desirability and prediction profile for the MPP are shown in Fig. 3 that emphasize the tendency and ranges of the main factors that affect the MPP. 
Table 3: Box-Behnken design for the most significant three variables that affected power generation (yeast extract $\left(\mathrm{X}_{1}\right)$, sodium acetate $\left(\mathrm{X}_{2}\right)$, and $\mathrm{MgSO}_{\text {.7. }} \mathrm{H}_{2} \mathrm{O}\left(\mathrm{X}_{3}\right)$ ).

\begin{tabular}{cccc}
\hline & & \multicolumn{2}{c}{ Variable } \\
\cline { 2 - 4 } & $\mathbf{\mathbf { X } _ { \mathbf { 1 } }}$ & $\mathbf{X}_{\mathbf{2}}$ & $\mathbf{X}_{\mathbf{3}}$ \\
$\mathbf{1}$ & $5(0)$ & $6(-)$ & $0.71(+)$ \\
$\mathbf{3}$ & $5(0)$ & $6(-)$ & $0.51(-)$ \\
$\mathbf{4}$ & $5(0)$ & $8(0)$ & $0.61(0)$ \\
$\mathbf{5}$ & $4(-)$ & $10(+)$ & $0.61(0)$ \\
$\mathbf{6}$ & $5(0)$ & $10(+)$ & $0.51(-)$ \\
$\mathbf{7}$ & $6(+)$ & $8(0)$ & $0.51(-)$ \\
$\mathbf{8}$ & $6(+)$ & $6(-)$ & $0.61(0)$ \\
$\mathbf{9}$ & $5(0)$ & $8(0)$ & $0.61(0)$ \\
$\mathbf{1 0}$ & $6(+)$ & $10(+)$ & $0.61(0)$ \\
$\mathbf{1 1}$ & $4(-)$ & $6(-)$ & $0.61(0)$ \\
$\mathbf{1 2}$ & $5(0)$ & $8(0)$ & $0.61(0)$ \\
$\mathbf{1 3}$ & $4(-)$ & $8(0)$ & $0.71(+)$ \\
$\mathbf{1 4}$ & $4(-)$ & $8(0)$ & $0.51(-)$ \\
\hline & $6(+)$ & $8(0)$ & $0.71(+)$ \\
\hline
\end{tabular}

The calculated regression equation for the optimization of media constituents assessed power generation ( $\mathrm{Y}$ ) as a function of these variables. By applying quadratic regression analysis on the experimental data, the following equation was found to explain power generation:

$$
\begin{aligned}
Y= & -2266+486 X_{1}+304 X_{2}-24 X_{3}-5.88 X_{1} X_{2}-68.0 X_{1} X_{3}-171 X_{2} X_{3}-37.6 X_{1}^{2}- \\
& 9.42 X_{2}^{2}+1576 X_{3}^{2}
\end{aligned}
$$

Where, $Y$ is the dependent variable (MPP) in $\mathrm{mW} / \mathrm{m}^{2} ; \mathrm{X}_{1}, \mathrm{X}_{2}$ and $\mathrm{X}_{3}$ are the concentrations of the independent variables as shown in (Table 4). 
Table 4. Results of Box-Behnken design experiment.

\begin{tabular}{cccccccc}
\hline Run & $\begin{array}{c}\text { Electric } \\
\text { current } \\
\mathbf{I}_{(33 \Omega)} \\
(\mathbf{m A})\end{array}$ & $\begin{array}{c}\text { Voltage } \\
\mathbf{E}_{\mathbf{( 3 3} \Omega)} \\
(\mathbf{m V})\end{array}$ & $\begin{array}{c}\text { Current } \\
\mathbf{d e n s i t y} \\
\mathbf{I}_{\mathbf{d}} \\
\left(\mathbf{m A} / \mathbf{c m}^{2}\right)\end{array}$ & $\begin{array}{c}\text { Electric } \\
\text { power } \\
\mathbf{P} \\
(\mathbf{m W})\end{array}$ & $\begin{array}{c}\text { Power } \\
\text { density } \\
\mathbf{M P P} \\
\left(\mathbf{m W} / \mathbf{m}^{2}\right)\end{array}$ & $\begin{array}{c}\text { Volumetric } \\
\text { Power } \\
\text { density } \\
\mathbf{P}_{\mathbf{v}(\mathbf{A n})} \\
\left(\mathbf{m W} / \mathbf{m}^{\mathbf{3}}\right)\end{array}$ & $\begin{array}{c}\text { Percentage of } \\
\text { improvement } \\
\text { in power } \\
\text { density }\end{array}$ \\
\hline $\mathbf{1}$ & 0.780 & 26.00 & 0.132 & 20.29 & 344.4 & 10.906 & -1.60 \\
$\mathbf{2}$ & 0.644 & 21.48 & 0.109 & 13.84 & 235 & 7.442 & -32.86 \\
$\mathbf{3}$ & 0.786 & 26.21 & 0.134 & 20.62 & 350 & 11.083 & 0.00 \\
$\mathbf{4}$ & 0.734 & 24.47 & 0.125 & 17.96 & 305 & 9.658 & -12.86 \\
$\mathbf{5}$ & 0.819 & 27.31 & 0.139 & 22.38 & 380 & 12.033 & 8.57 \\
$\mathbf{6}$ & 0.774 & 25.80 & 0.131 & 19.97 & 339 & 10.735 & -3.14 \\
$\mathbf{7}$ & 0.688 & 22.94 & 0.117 & 15.79 & 268 & 8.487 & -23.43 \\
$\mathbf{8}$ & 0.786 & 26.21 & 0.134 & 20.62 & 350 & 11.083 & 0.00 \\
$\mathbf{9}$ & 0.758 & 25.26 & 0.129 & 19.14 & 325 & 10.292 & -7.14 \\
$\mathbf{1 0}$ & 0.596 & 19.86 & 0.101 & 11.84 & 201 & 6.365 & -42.57 \\
$\mathbf{1 1}$ & 0.786 & 26.21 & 0.134 & 20.62 & 350 & 11.083 & 0.00 \\
$\mathbf{1 2}$ & 0.765 & 25.49 & 0.130 & 19.50 & 331 & 10.482 & -5.43 \\
$\mathbf{1 3}$ & 0.705 & 23.49 & 0.120 & 16.55 & 281 & 8.898 & -19.71 \\
$\mathbf{1 4}$ & 0.800 & 26.65 & 0.136 & 21.31 & 361.8 & 11.457 & 3.37 \\
$\mathbf{1 5}$ & 0.790 & 26.32 & 0.134 & 20.79 & 352.9 & 11.175 & 0.83 \\
\hline
\end{tabular}

Table 5: Analysis of variance for the fitted quadratic polynomial model.

\begin{tabular}{ccccc}
\hline & Coefficients & Standard Error & $\boldsymbol{t}$ Stat & $\boldsymbol{P}$-value \\
\cline { 2 - 5 } Intercept & -2265.98 & 65.87665 & -34.3973 & $3.91 \mathrm{E}-07$ \\
$\mathbf{X}_{\mathbf{1}}$ & 486.08 & 12.31472 & 39.47146 & $1.97 \mathrm{E}-07$ \\
$\mathbf{X}_{\mathbf{2}}$ & 303.8625 & 5.558238 & 54.66885 & $3.87 \mathrm{E}-08$ \\
$\mathbf{X}_{\mathbf{3}}$ & -24.15 & 137.747 & -0.17532 & 0.867706 \\
$\mathbf{X}_{\mathbf{1}} \mathbf{X}_{\mathbf{2}}$ & -5.875 & 0.483703 & -12.1459 & $6.69 \mathrm{E}-05$ \\
$\mathbf{X}_{\mathbf{1}} \mathbf{X}_{\mathbf{3}}$ & -68 & 9.674063 & -7.0291 & 0.000899 \\
$\mathbf{X}_{\mathbf{2}} \mathbf{X}_{\mathbf{3}}$ & -170.625 & 4.837032 & -35.2747 & $3.45 \mathrm{E}-07$ \\
$\mathbf{X}_{\mathbf{1}}{ }^{2}$ & -37.5625 & 1.006908 & -37.3048 & $2.61 \mathrm{E}-07$ \\
$\mathbf{X}_{\mathbf{2}}^{\mathbf{2}}$ & -9.42187 & 0.251727 & -37.4289 & $2.56 \mathrm{E}-07$ \\
$\mathbf{X}_{\mathbf{3}}^{\mathbf{2}}$ & 1576.25 & 100.6908 & 15.65435 & $1.93 \mathrm{E}-05$ \\
\hline
\end{tabular}




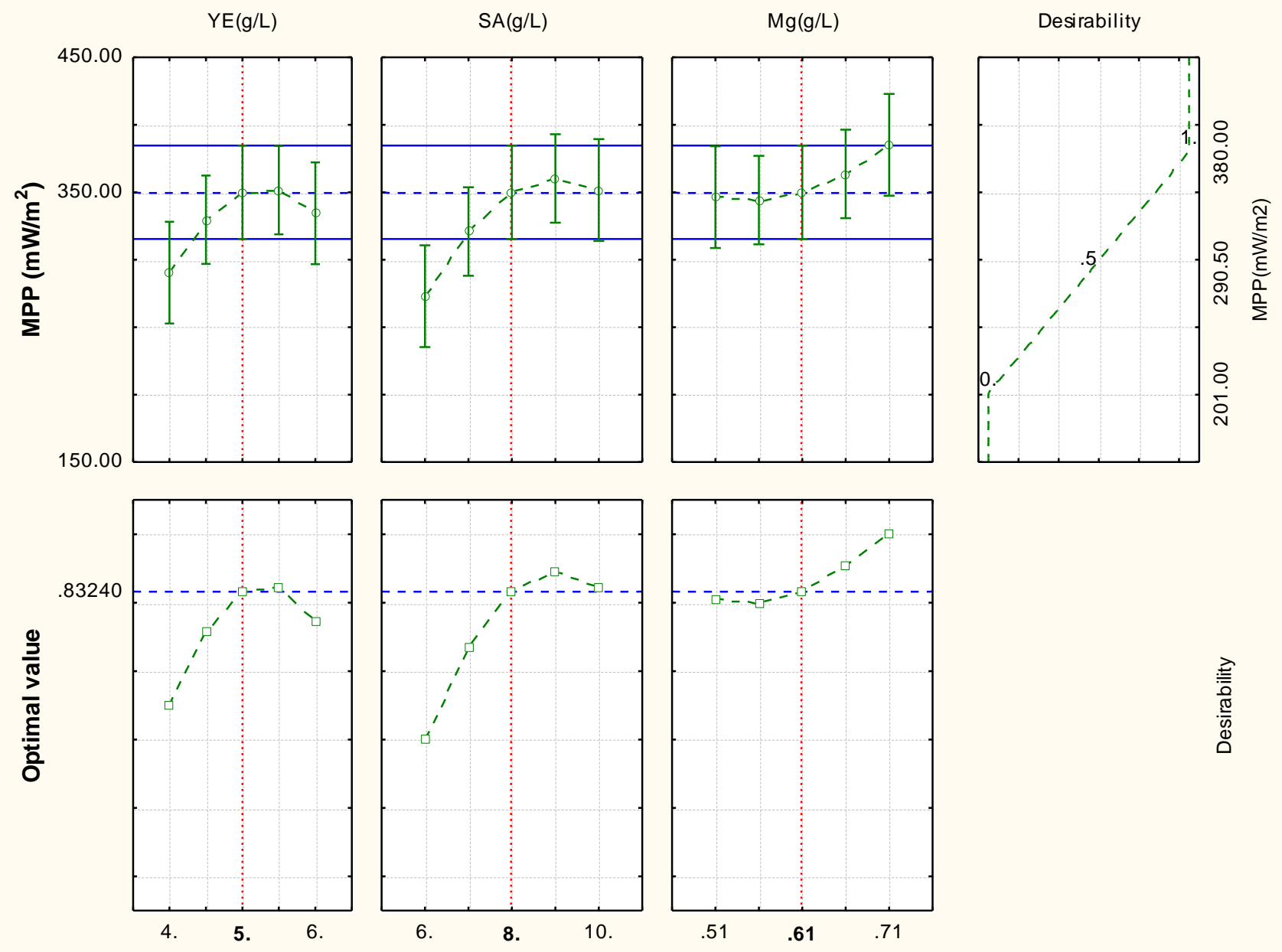

Fig.3: Desirability and prediction profile for the MPP in Box-Behnken design.

Normally, a regression model having an $\mathrm{R}^{2}$ value higher than 0.9 is considered as having a very high correlation and a model with an $\mathrm{R}^{2}$ value between 0.7 and 0.9 is considered as having a high correlation (Guilford and Fruchter, 1973; Haaland, 1989). That means, in the present case, the coefficient of determination, i.e., $\mathrm{R}^{2}$, was 0.9997. This means that $99.97 \%$ reflected a very good fit between the observed and predicted responses and it was reasonable to use the regression model to analyze the trends in the responses.

Using a confidence interval of $95 \%$, the analysis suggested that, the factors that affected the response significantly were; yeast extract, sodium acetate $(P<0.05)$, square of yeast extract, sodium acetate, $\mathrm{MgSO} 4.7 \mathrm{H}_{2} \mathrm{O}(P<0.05)$, and the interaction between yeast extract and sodium acetate, yeast extract and $\mathrm{MgSO}_{4} \cdot 7 \mathrm{H}_{2} \mathrm{O}$, sodium acetate and $\mathrm{MgSO}_{4} .7 \mathrm{H}_{2} \mathrm{O}(P<0.05)$. According to the polynomial equation, all these factors except the concentration of yeast extract and sodium acetate had a negative effect on power generation.

The three dimensional response surface plots are graphical representations of the regression equation. Higher responses were observed for high concentration of yeast 
extract and sodium acetate (Fig.4A), high concentration of yeast extract and $\mathrm{MgSO}_{4} .7 \mathrm{H}_{2} \mathrm{O}$ (Fig.4B); and high concentration of sodium acetate and low concentration of $\mathrm{MgSO}_{4} .7 \mathrm{H}_{2} \mathrm{O}$ (Fig.4C).

(A)

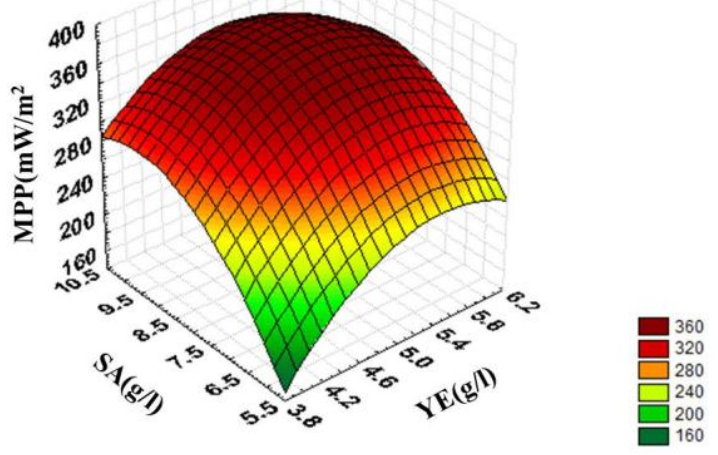

(B)

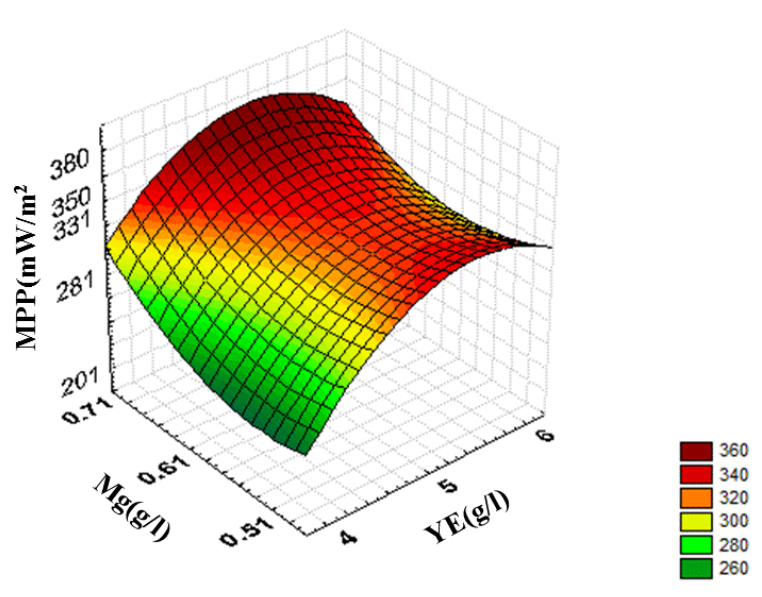

(C)

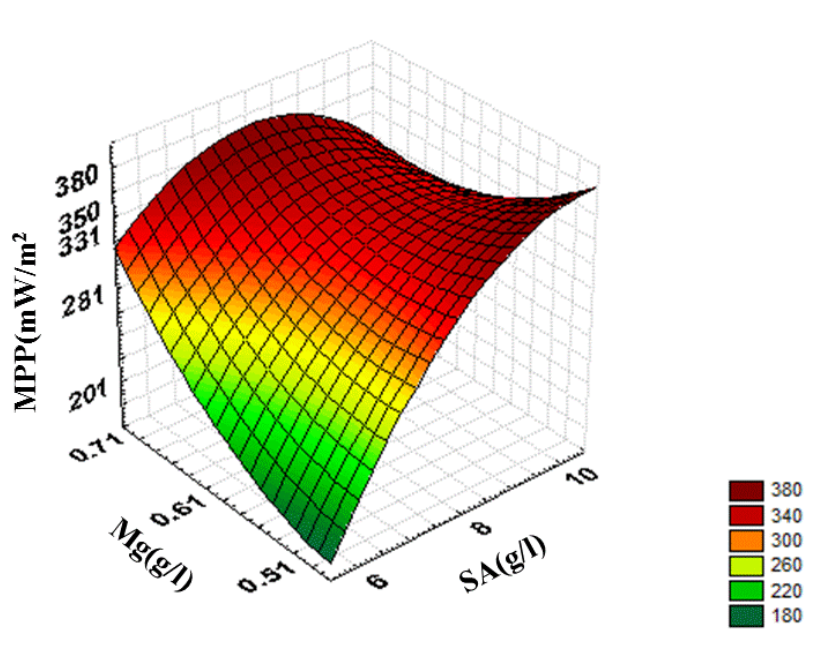

Fig.4: Response surface of the interaction of (A) yeast extract and sodium acetate, (B) yeast extract and $\mathrm{MgSO}_{4} \cdot 7 \mathrm{H}_{2} \mathrm{O}$ and (C) sodium acetate and $\mathrm{MgSO}_{4} \cdot 7 \mathrm{H}_{2} \mathrm{O}$ on power generation. 
These trends in response surfaces suggested the use of a medium containing elevated concentrations of yeast extract, sodium acetate and low concentration of $\mathrm{MgSO}_{4} \cdot 7 \mathrm{H}_{2} \mathrm{O}$. It is important to understand why these three components were identified as critical factors for power generation, i.e., yeast extract, sodium acetate, and $\mathrm{MgSO}_{4} \cdot 7 \mathrm{H}_{2} \mathrm{O}$. The effect of yeast extract is likely because it is the source of nitrogen, which is very important for the cell, as it is an integral component of amino acids, proteins and nucleic acids. Tiwari et al. (2018), who tested the effect of four different nitrogen sources on power output of MFC, reported that the presence of any of the tested nitrogen sources, increased the electricity generation by almost the double, when compared with a cell running with no nitrogen source added.

The effect of sodium acetate is likely because carbon compounds are the sources of carbon skeleton and energy for bacterial cell growth and hence increased the power generation (Ong and Yamagiwa, 2018). Webb (1951) reported that in complex media, conditions of magnesium deficiencies or excess were found to inhibit the process of cell division, where as in simple chemically-defined media, these conditions predominantly limited growth (i.e. synthesis of cell substances). The optimum concentration of the three independent variables as obtained from the maximum point of the model were calculated using Microsoft Excel 2010 solver, and were found to be; yeast extract, $5.2 \mathrm{~g} / \mathrm{l}$; sodium acetate, $8.1 \mathrm{~g} / \mathrm{l}$ and $\mathrm{MgSO}_{4} \cdot 7 \mathrm{H}_{2} \mathrm{O}, 0.71 \mathrm{~g} / \mathrm{l}$. Response "Y" of MPP predicted by applying these levels is $386.74 \mathrm{~mW} / \mathrm{m}^{2}$.

\section{Verification of the optimized results}

According to Box-Behnken and Plackett- Burman experimental results, an optimum response for power generation is predicted with the following medium composition: PBS, 25mM; YE, $5.2 \mathrm{~g} / \mathrm{l} ; \mathrm{SA}, 8.1 \mathrm{~g} / \mathrm{l} ; \mathrm{Mg}, 0.71 \mathrm{~g} / \mathrm{l}$; VI, $1 \mathrm{ml}$; and MB, $240 \mu \mathrm{M}$. A confirmatory experiment for maximal power generation was performed under the predicted optimal condition, where MPP was estimated after 10 days of performing the MFC. A basal culture medium was used as a control. Under the optimized condition, the MPP was 390 $\mathrm{mW} / \mathrm{m}^{2}$. These results indicate that the optimized conditions accelerated the power generation and the MPP was about $91.2 \%$ higher than that recorded with the basal condition $\left(204 \mathrm{~mW} / \mathrm{m}^{2}\right)$. Matching the predicted MPP $\left(386.74 \mathrm{~mW} / \mathrm{m}^{2}\right)$ and the observed one $\left(390 \mathrm{~mW} / \mathrm{m}^{2}\right)$ under optimal condition also proved the accuracy and validity of the model.

\section{CONCLUSION}

Recent researches are focused on the use of the MFC technology for wastewater treatment while simultaneously generating electricity. If the performance of this technology was successfully improved to be applicable on a larger scale, it would not only save us time and energy, but also would help in the utilization of what would otherwise be considered as waste. Researchers are trying to make this technology applicable on a larger scale and are trying to enhance the power produced by the cell. If successfully applied on a large scale, microbial fuel cells would be of great promise especially in developing countries where water treatment, when available, is very limited due to economic and political issues. Other applications of microbial fuel cell technology 
include the use in powering implanted medical devices (e.g. the pace maker), and powering environmental sensors. MFCs can also be modified to produce valuable chemicals (e.g. hydrogen and caustic soda).

Author of conflict: There is no author of conflict

\section{REFERENCES}

Alshehri, A.N.Z.; Ghanem, K.M. and Algarni, S.M. (2016) Application of a five level central composite design to optimize of operating conditions for electricity generation in microbial fuel cell, J. of Taibah Uni. Sci., 10(6): 797-804. http://dx.doi.org/10.1016/j.jtusci.2015.01.004.

Anderson, V.L. and McLean, R.A. (2018) Design of Experiments: A Realistic Approach, 5:1-415.

Annadurai, G.; Ling, L.Y. and Lee, J.F. (2008) Statistical optimization of medium components and growth conditions by response surface methodology to enhance phenol degradation by Pseudomonas putida. J. Hazar. Mate., 151: 171-178.

Bin Halmi, M.I.E.; Abdullah, S.R.S.; Wasoh, H.; Johari, W.L.W.; bin Mohd Ali, M.S.; Shaharuddin, N.A. and Shukor, M.Y. (2016) Optimization and maximization of hexavalent molybdenum reduction to Mo-blue by Serratia sp. strain MIE2 using response surface methodology. Rend. Fis. Acc., 27: 697-709

Box, G.E.P. and Behnken, D.W. (1960) Some new three level designs for the study of quantitative variables. Technomet., 2: 455-475.

Cao, T.N.D.; Chen, S.S.; Ray, S.S.; Le, H.Q. (2019) Chang, H.M. Application of Microbial Fuel Cell in Wastewater Treatment and Simultaneous Bioelectricity Generation. In: Bui XT.; Chiemchaisri, C.; Fujioka, T. and Varjani, S. (eds) Water and Wastewater Treatment Technologies. Energy, Environment, and Sustainability. Springer, Singapore. doi.org/10.1007/978-981-13-3259-3_23.

Deng, L.Y.; and Tang, B. (1999) Generalized Resolution and Minimum Aberration Criteria for Plackett-Burman and Other Nonregular Factorial Designs. Statistica Sinica, 9: 1071-1082.

El-Badan D.; Khaled M. and Ghanem K. (2019) A sustainable bioelectricity production from wastewater. Egyp. J. Aqu. Biol.Fishe., 23(5): 225-233.

Ferreira, S.L.C.; Bruns, R.E.; Da Silva, E.G.P.; Santos, W.N.L.D.; Quintella, C.M.; David, J.M.; De Andrade,J.B.; Breitkreitz,M.C.; Jardimb,I.C.S.F. and Neto, B.B. (2007) Statistical design and response surface techniques for the optimization of chromatographic systems. J. Chrom., 1158(1-2): 2-14.

Flimban, S.G.A.; Kim, T.; Ismail, I.M.I. and Oh, S.E. (2018) Overview of Microbial Fuel Cell (MFC) Recent Advancement from Fundamentals to Applications: MFC Designs, Major Elements, and Scalability. doi:10.20944/PREPRINTS201810.0763.V1.

Ghanem, K.M, Al-Garni, S.M. and Al Homodia, A.F. (2015) Biodegradation of kerosene by Asepergillus flavus using statistical experimental designs. Biorem. J., 19: 69-79.

Ghanem, K.M, Al-Garni, S.M. and Al-Zahrani, M.A. (2016) Bioremediation of Diesel Fuel by Fungal Consortium Using Statistical Experimental Designs. Pol. J. Environ. Stud., 25(1): 1-10, DOI: 10.15244/pjoes/42493 
Guilford, J.P. and Fruchter, B. (1973) Fundamental statistics in psychology and education .NewYork:McGraw-Hill,pp. 154-155.

Haaland, P.D. (1989) Experimental design in Biotechnology, Marcel Decker, New York

Huang, J.; Zhang, G.; Zheng, L.; Lin, Z.; Wu, Q. and Pan, Y. (2019). Plackett-Burman design and response surface optimization of conditions for culturing Saccharomyces cerevisiae in Agaricus bisporus industrial wastewater. Acta Sci. Pol. Technol. Aliment., 18(1): 65-74. http://dx.doi.org/10.17306/J.AFS.2019.0620

Logan, B. E. (2008). Microbial Fuel Cells. John Wiley \& Sons.

Mabrouk, M.E.M.; ElAhwany, A.M.D.; Beliah, M.M.B. and Sabry, S.A. (2013) Xanthan production by a novel mutant strain of Xanthomonas campestris: Application of statistical design for optimization of process parameters. Life Sci. J.; 10: 16601667.

Mabrouk, M.E.M.; Youssif, E.M. and Sabry, S.A. (2014) Biosurfactant production by a newly isolated soft coral-associated marine Bacillus sp.E34: Statistical optimization and characterization. Life Sci. J., 11(10): 756-768.

Mahmoodi-Babolan, N.; Heydari, A. and Nematollahzadeh, A. (2019) Removal of methylene blue via bioinspired catecholamine/starch super adsorbent and the efficiency prediction by response surface methodology and artificial neural network-particle swarm optimization, 294. https://doi.org/10.1016/j.biortech.2019.122084

Mohajeri Amiria, M.; Fazelib, M.R.; Babaeeb, T.; Aminic, M.; Roodbaria, N.H.; Mousavid, S.B. and Samadi, N. (2019) Production of Vitamin D3 Enriched Biomass of Saccharomyces Cerevisiae as A Potential Food Supplement: Evaluation and Optimization of Culture Conditions Using Plackett-Burman and Response Surface Methodological Approaches. Iran. J. Pharm. Res., 18 (2): 974-987 DOI: 10.22037/ijpr.2019.1100660

Montgomery, D.C. (2012) Two-level fractional factorial designs. In Montgomery, D. C. Design and analysis of experiments, $8^{\text {th }}$ Edition $\left(8^{\text {th }}\right.$ ed., p. 730$)$. John Wiley \& Sons.

Ong, A.A and Yamagiwa, K. (2018) Evaluation on the electricity generation using membrane-less fixed-bed upflow microbial fuel cell. Rend. Fis. Acc., 29(1): 103107

Parkash, A. (2016) Characterization of generated voltage, current, power and power density from cow dung using double chambered microbial fuel cell. J. Phys. Chem. Biophys., 6: 208. doi:10.4172/2161-0398.1000208

Scibilia, B. (2014) How Could you benefit from Plackett-Burman experimental designs ? The Minitab Blog: http://blog.minitab.com/blog/applying-statistics-in-qualityprojects/how-could-you-benefit-from-Plackett-Burman-experimental-designs

Selamat, S.N.; Bin Halmi, M.E.; Abdullah, S.R.S.; Idris, M.; Abu Hasan, H. and Anuar, N. (2018) Optimization of lead (Pb) bioaccumulation in Melastoma malabathricum L. by response surface methodology (RSM). Rend. Fis. Acc., 29(1): 43-51

Slate, A.J.; Whitehead, K.A.; Brownson, D.A.C. and Banks, C.E. (2019) Microbial fuel cells: An overview of current technology. Renew. Sustain. Ene. Rev., 101: 60-81. doi:https://doi.org/10.1016/j.rser.2018.09.044. 
Strobel, R. and Sullivan, G. (1999) Experimental design for improvement of fermentations. In: Demain, A.L.; Davies, J.E.; eds. Manual of Industrial Microbiology and Biotechnology. Washington: ASM Press, pp. 80-93.

Thygesen, A.; Poulsen, F. W.; Min, B.; Angelidaki, I. and Thomsena, A. B. (2009) The effect of different substrates and humic acid on power generation in microbial fuel cell operation. Bioreso. Techn. J., 100: 1186-1191. doi:10.1016/j.biortech.2008.07.067

Tiwari, B. R.; Noori, Md. T. and Ghangrekar, M. M. (2018). Enhancing performance of microbial fuel cell treating distillery wastewater using carbon supported Nickelphthalocyanine/MnOx as novel cathode catalyst. MRS Advances , 3 (13): 657-662. DOI: $10.1557 / \mathrm{adv} .2018 .73$.

Ulusoy, I. and Dimoglo, A. (2018). Electricity generation in microbial fuel cell systems with Thiobacillus ferrooxidans as the cathode microorganism. Int. J. Hyd. Ene., 43: 1171-8. doi:https://doi.org/10.1016/j.ijhydene.2017.10.155.

Uwadiae, S.E. and Ihaza, O.E. (2018) Optimization of process parameters in treatment of brewery effluent. Acta Technica Corviniensi- Bulletin of Engineering Tome XI

Vilas Boas, J.; Oliveira, V.B.; Marcon, L.R.C.; Simões, M. and Pinto, A.M.F.R. (2019). Optimization of a single chamber microbial fuel cell using Lactobacillus pentosus: Influence of design and operating parameters. Sci Total Env., 648: 263-70.

Webb,M. (1951) The influence of magnesium on cell division . J.Gen. Microb., 5: 496-501.

Xu, G.; Zheng, X.; Lu, Y.; Liu, G.; Luo, H.; Li, X.; Zhang, R. and Jin, S. (2019). Development of microbial community within the cathodic biofilm of single-chamber air-cathode microbial fuel cell. Sci. Total Env., 665: 641-648. doi:https://doi.org/10.1016/j.scitotenv.2019.02.175.

Yong, X.; Raza, W.; Yu, G.; Ran, W.; Shen, Q. and Yang, X. (2011). Co-producing ipopeptides and poly-Y-glutamic acid by solid -state fermentation of Bacillus subtilis using soybean and sweet potato residues and its biocontrol and fertilizer synergistic effect. Biores. Techn., 99: 3318-3323. 